\title{
EFFECT OF THE PINEAL GLAND AND MELATONIN ON DOPAMINE RELEASE FROM PERIFUSED HYPOTHALAMUS OF MATURE FEMALE CARP DURING SPAWNING AND WINTER REGRESSION
}

\author{
Włodzimierz POPEK ${ }^{1}$, Ewa EUSZCZEK-TROJNAR ${ }^{1^{*}}$, Ewa DRĄG-KOZAK ${ }^{1}$, \\ Danuta FORTUNA-WROŃSKA ${ }^{2}$, Piotr EPLER ${ }^{1}$ \\ ${ }^{1}$ Division of Ichthyobiology and Fisheries, ${ }^{2}$ Division of Animal Physiology; \\ Agricultural University in Kraków, Poland
}

Popek W., Łuszczek-Trojnar E., Drąg-Kozak E., Fortuna-Wrońska D., Epler P. 2005. Effect of the pineal gland and melatonin on dopamine release from perifused hypothalamus of mature female carp during spawning and winter regression. Acta Ichthyol. Piscat. 35 (2): 65-71.

\begin{abstract}
Background. Melatonin regulates various physiological and neuroendocrinological processes that occur rhythmically, and stimulates or inhibits endocrine activity of various body glands. This acts on the hypothalamic-pituitary-gonadal axis by synchronizing animals with their reproductive cycles. The proximity of melatonin receptors and dopamine and gonadoliberin production sites has led to a hypothesis that dopamine may be a link between melatonin and hypothalamic LHRH. Melatonin may have an indirect influence on animal reproduction through dopaminergic structures of the hypothalamus, but the mechanism involved remains unknown, also in fish, for this reason, the present experiment was conducted. The aim of the study was to determine the effect of melatonin on dopamine release from hypothalamic cells of mature female carp in vitro.

Material and Methods. Hypothalami were perifused with a mineral medium containing melatonin (group 1), in the presence of implanted pineal glands (group 2), and with a pure mineral medium (control). Perifusion was $180 \mathrm{~min}$ long and samples of the effluent perifusate were collected at 15-minute intervals. Dopamine concentration in the medium was analysed radioenzymatically. The experiment was carried out in the summer during spawning and in the winter during regression.
\end{abstract}

Results. The results indicate that melatonin inhibits the release of dopamine from hypothalamic cells. This effect was only noticeable in the experiment conducted during the spawning period.

Conclusion. The present findings show that melatonin may have a role in the hypothalamic control of hypophyseal activity during the spawning period of carp.

Key words: pineal gland, melatonin, dopamine, perifusion, carp, fish

\section{INTRODUCTION}

Dopamine is one of catecholamines produced in the brain by hypothalamic aminergic nuclei NRL (nucleus recessus lateralis) and NRP (nucleus recessus posterioris). It inhibits gonadotropin LH secretion by activating dopamine D2 receptors found on gonadotropic cells of the pituitary gland (Peter et al. 1986, Omeljaniuk et al. 1987). The inhibiting effect of dopamine is not limited to the pituitary gland, because studies with crucian carp proved its inhibitory effect on both LHRH synthesis and secretion (Yu and Peter 1990). This hypothesis was also confirmed by in vitro studies (Yu et al. 1991, Yu and Peter 1992). The release of LHRH by the dopamine $D 2$ receptor is inhibited probably via neuronal projections of neighbouring dopamine fibres and LHRH fibres (Yu and Peter 1992).
Melatonin, whose concentration in the pineal gland and in the peripheral blood is highest at night and lowest during the day (Reiter 1991a), serves as an indicator of a biochemical biological clock. Melatonin synthesis and secretion, which occurs only during the night, delivers to the central nervous system an endocrine signal proportional to the length of the night (Reiter 1991b). This hormone regulates various physiological and neuroendocrinological processes that occur rhythmically, and stimulates or inhibits endocrine activity of various body glands.

This is particularly important for seasonally breeding species, in which photoperiod is the main environmental cue informing the pineal gland of annual changes in the day length. At the same time, this gland acts through its hormone melatonin on the hypothalamic-pituitary-gonadal axis by synchronizing animals with

\footnotetext{
* Correspondence: Dr Ewa Łuszczek-Trojnar, Katedra Ichtiobiologii i Rybactwa Akademii Rolniczej w Krakowie, ul. Spiczakowa 6, 30-199 Kraków-Mydlniki, phone: (+48) 12 637-5176, fax: (+48) 12 638-5979, e-mail: etrojnar@wp.pl
} 
their reproductive cycles (Reiter 1991a, b, Zachmann et al. 1991).

In looking for a link between the pineal gland and the hypothalamus, Zisapel and Laudon (1983) and Zisapel et al. (1985) showed that melatonin is able to inhibit dopamine secretion from the hypothalamic cells of the rat. The results of other studies, which showed that even picomolal concentrations of melatonin can inhibit dopamine release from the retina of birds and mammals (Cardinali et al. 1979, Dubocovich 1983, 1985), seemed to support this theory. Also in humans, the high nocturnal level of melatonin reduces dopaminergic activity in the hypothalamus (Rao and Mager 1987). In the brain of mammals, melatonin receptors are most abundant in the hypothalamus and in the anterior lobe of the pituitary gland, and much less abundant in the other parts of the brain (Weaver et al. 1991, Stankov et al. 1993). It is therefore conjectured that the hypothalamus acts as a functional link between melatonin and the endocrine system (Maywood et al. 1996). In the hypothalamus, the highest concentration of melatonin receptors is found in the medial eminence, next to the arcuate nucleus (Weaver et al. 1989). In mammals, this area also contains endings of axons from LHRH-producing cells and neurons of the tubero-infundibular system containing dopamine. Dopamine, by inhibiting LHRH release to the capillaries of the pituitary portal circulation (Wuttke et al. 1971), controls LH and FSH secretion from the pituitary gland of mammals (Gallo 1980, 1981). The proximity of melatonin receptors and dopamine and gonadoliberin production sites has led to a hypothesis that dopamine may be a link between melatonin and hypothalamic LHRH.

The studies with carp have revealed that nocturnal injections of melatonin (dark phase) into mature female carp increase the level of maturation gonadotropin (LH) in blood (Breton et al. 1993). It was also demonstrated that melatonin modulates the activity of the hypothalamic dopaminergic system rather that directly affecting gonads or the pineal gland (Popek 1991, Popek et al. 1994a, Popek and Epler 1999).

The above body of evidence suggests that melatonin may have an indirect influence on animal reproduction through dopaminergic structures of the hypothalamus, but the mechanism involved remains unknown, also in fish. Therefore, the aim of the present experiment was to investigate the effects of the pineal gland and melatonin on dopamine secretion from the hypothalamus not controlled by the body, under in vitro conditions.

The effect of melatonin on the activity of hypothalamic aminergic nuclei is seasonal (Popek 1991, Popek and Epler 1999), as is variation in the rhythm of catecholamine release in the hypothalamus (Popek et al. 1994a). For this reason, the present experiment was conducted in two seasons of the year: in the spawning season of carp in June, and during gonadal regression in December. This experimental design allowed us to determine if the effect of melatonin on dopamine release from hypothalamic aminergic nuclei is season dependent.

\section{MATERIALS AND METHODS}

A total of 30 mature female common carp, Cyprinus carpio L., were used. The experiments were carried out twice a year.

Prior to each experiment, fish were decapitated and their hypothalami and pineal glands were removed as rapidly as possible (within 1 minute on average) and placed on ice. Hypothalami (with an average unit weight of 220 $\mathrm{mg}$ ) were cut with a scalpel into 3-mm-thick slices and were individually placed on a Biogel in 15 perifusion columns of $5 \mathrm{~mL}$ volume. Aerated mineral medium in the form of Cortland buffered salt solution was pumped through the columns (Jalabert et al. 1973). The 15-channel peristaltic pump (Zalimp - PP 1B-05) used made it possible to maintain a continuous controlled flow $(8 \mathrm{~mL}$ per hour) of the perifusion medium. The set contained also a luxmeter sensor placed next to the perifusion columns, whereby the light regime during the experiment could be controlled. Two 11-W Lival halogen lamps provided uniform illumination of the set, producing light of constant 2000 lx intensity (Fig. 1). The set was wrapped in aluminium foil and the light was turned off to ensure complete darkness (0 lx).

Perifusion was performed in three groups (each having 5 perifusion columns):

Group 1, with hypothalami perifused in a medium containing melatonin at a concentration of $300 \mathrm{pg} \cdot \mathrm{mL}^{-1}$ (MT); Group 2, with hypothalami into which three pineal glands were implanted (P); Group 3, with hypothalami perifused in a pure medium, constituting control group (C).

Melatonin (Sigma) was predissolved in $5 \mu \mathrm{L}$ of $96 \%$ ethanol and then in perifusion medium. Temperature of the medium was $22^{\circ} \mathrm{C}$.

Perifusion was 180 minutes long. The columns were illuminated (2000 lx) during the first 60 minutes of the experiment and kept in complete darkness for the next 120 minutes of perifusion. Samples of the effluent perifusate were taken using an automatic collector at 15-minute intervals, frozen at $-60^{\circ} \mathrm{C}$, and stored until the level of dopamine was determined.

Summer period (June, water temperature $22^{\circ} \mathrm{C}$, $\mathbf{L}: \mathbf{D}=\mathbf{1 6}: \mathbf{8})$. Fifteen fish weighing an average of $2.4 \mathrm{~kg}$ $( \pm 0.16)$ were investigated. Fish before the experiment, tissues in perifusion columns, and the perifusion medium were kept at $22^{\circ} \mathrm{C}$ throughout.

Winter period (December, water temperature $5^{\circ} \mathrm{C}$, $\mathbf{L}: \mathbf{D}=\mathbf{8}: \mathbf{1 6}$ ). Fifteen fish weighing an average of $2.8 \mathrm{~kg}$ $( \pm 0.24)$ were investigated. Division into groups and the perifusion method were the same as in the summer experiment. Only temperatures of water in the pond in which fish were kept prior to the experiment, tissues in columns and the perifusion medium were lower $\left(5^{\circ} \mathrm{C}\right)$.

Samples of the medium were analysed radioenzymatically to determine the level of dopamine (Johnson et al. 1980). The results were analysed using one-way analysis of variance and STATISTICA procedures were used to determine statistical differences between the groups. 


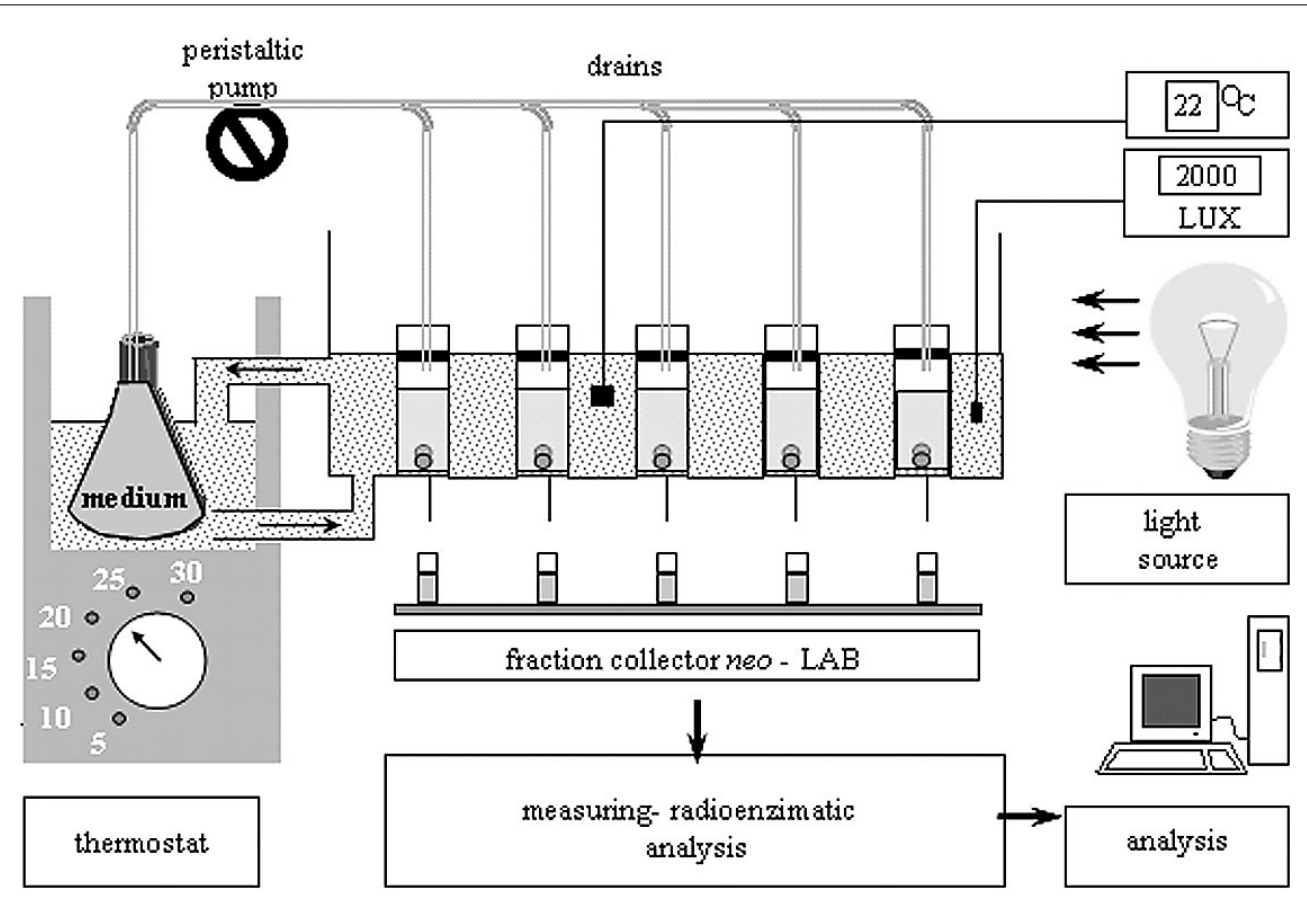

Fig. 1. Schematic diagram showing the flow of medium through the set of perifusion columns containing the analysed tissues

\section{RESULTS}

Summer period. During the summer, average dopamine concentration in the perifusion medium in group 1, in which hypothalami were perifused with a medium containing melatonin (MT), ranged from 0.431 $( \pm 0.06)$ to $0.983( \pm 0.13) \mathrm{pmol} \cdot \mathrm{mL}^{-1}$. The concentration of this hormone was the highest at the beginning of perifusion and decreased over the next 45 minutes to reach $0.522( \pm 0.06) \mathrm{pmol} \cdot \mathrm{mL}^{-1}$ at 60 minutes. From that time to the end of the experiment, dopamine concentration in the medium continued to be low, ranging from 0.711 $( \pm 0.12)$ to $0.573( \pm 0.05) \mathrm{pmol} \cdot \mathrm{mL}^{-1}$.

In group 2, in which pineal glands were implanted into hypothalami $(\mathrm{P})$, average dopamine level ranged from $0.53( \pm 0.03)$ to $1.188( \pm 0.25) \mathrm{pmol} \cdot \mathrm{mL}^{-1}$. The highest concentration of this hormone in the medium was found at 30 minutes of perifusion. From 60 minutes of perifusion (perifusion in darkness), dopamine concentration in the medium gradually decreased to reach the lowest value at 135 minutes of the experiment, and was significantly lower $(P<0.05)$ than during the first hour of perifusion.

In the control group (C), average dopamine concentration in the perifusion medium was $0.616( \pm 0.07)$ at the beginning, $0.562( \pm 0.08) \mathrm{pmol} \cdot \mathrm{mL}^{-1}$ at the end, and 1.529 $( \pm 0.09) \mathrm{pmol} \cdot \mathrm{mL}^{-1}$ at 90 minutes of the experiment.

Statistical analysis showed that dopamine level at 90 minutes of perifusion in groups 1 (MT) and $2(\mathrm{P})$ was highly significantly lower $(P<0.01)$ than in the control group $(\mathrm{C})$. Significant differences $(P<0.05)$ were also noticed at $30,60,75,105,120,135,150$, and 165 minutes of perifusion in group 1 .
The course of changes in dopamine concentration in the perifusion medium flowing through the columns with hypothalami of mature female carp during the summer is given according to groups in Fig. 2.

Winter period. Average DA concentration at the start of the experiment was similar in all the groups, ranging from $0.263( \pm 0.02)$ to $0.367( \pm 0.03) \mathrm{pmol} \cdot \mathrm{mL}^{-1}$. In the next samples taken during the next minutes of perifusion, DA concentration increased gradually in all the groups and at 105 minutes it reached $0.62( \pm 0.07) \mathrm{pmol} \cdot \mathrm{mL}^{-1}$ in group 1, where the medium was supplemented with melatonin, $0.469( \pm 0.05)$ in group 2 , in which hypothalami were perifused in the presence of pineal glands $(\mathrm{P})$, and $0.72( \pm 0.08) \mathrm{pmol} \cdot \mathrm{mL}^{-1}$ in the control group $(\mathrm{C})$.

Starting from 120 minutes of perifusion, DA concentration in the medium in all the groups slightly decreased, ranging at 180 minutes of perifusion from $0.38( \pm 0.04)$ to $0.51( \pm 0.06) \mathrm{pmol} \cdot \mathrm{mL}^{-1}$.

Statistical analysis did not show any highly significant $(P<0.01)$ differences in dopamine concentration in the medium between the groups. Significant differences $(P<0.05)$ were noticed between summer and winter periods in groups $2(\mathrm{P})$ and $3(\mathrm{C})$.

The course of changes in dopamine concentration in the perifusion medium flowing through the columns with hypothalami of mature female carp during the winter is shown according to group in Fig. 3.

\section{DISCUSSION}

The way in which melatonin affects reproductive processes in animals has puzzled scientists for a long time. Many hypotheses were put forward, some indicating that 


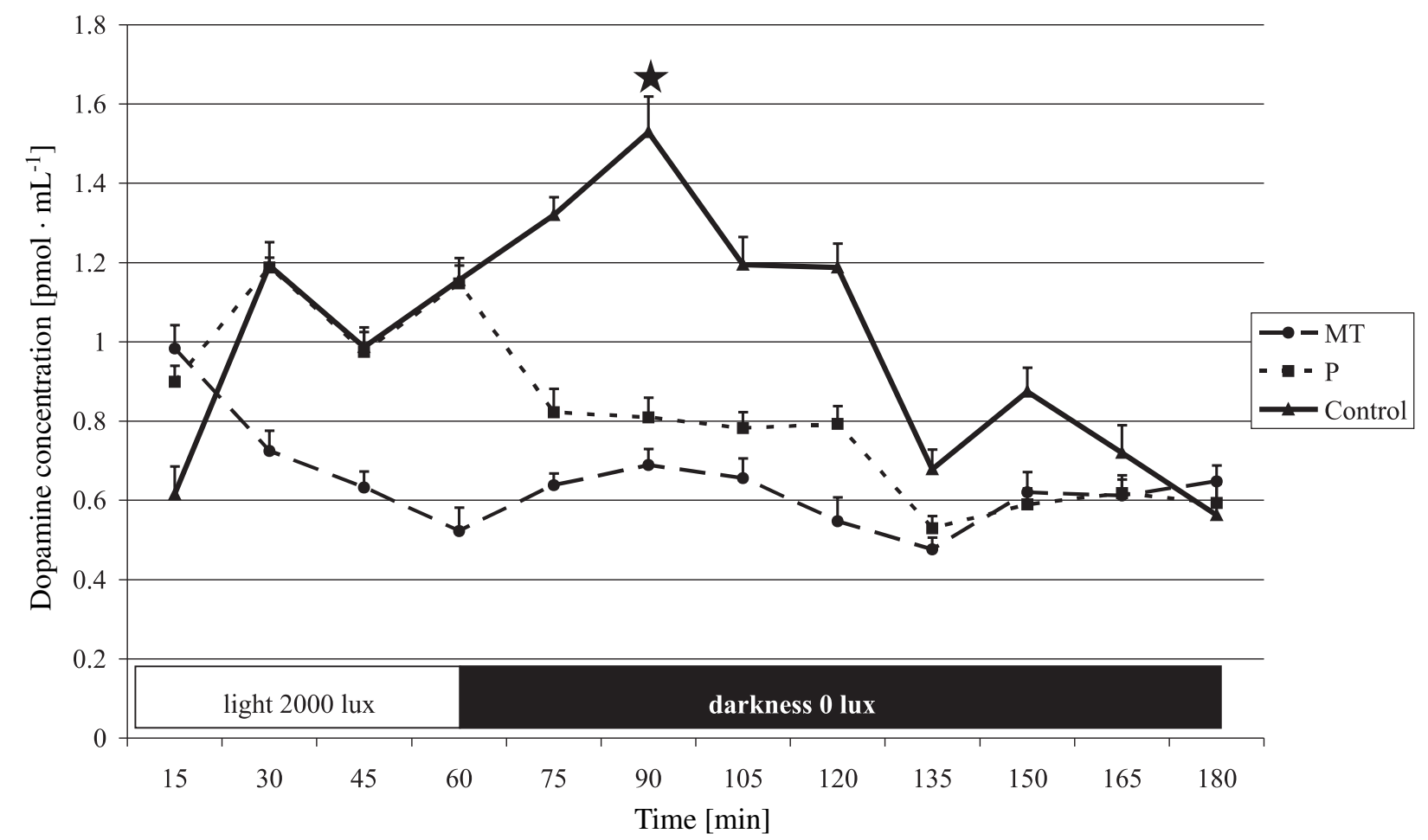

Fig. 2. Mean dopamine concentrations in the medium during hypothalamic perifusion of mature female carp in the summer $( \pm s)$; MT, hypothalami perifused in the presence of melatonin (dashed line); $\mathrm{P}$, hypothalami with implanted pineal glands (dotted line); $\mathrm{C}$, control hypothalami (solid line); $\star$ statistically significant difference $(P<0.01)$

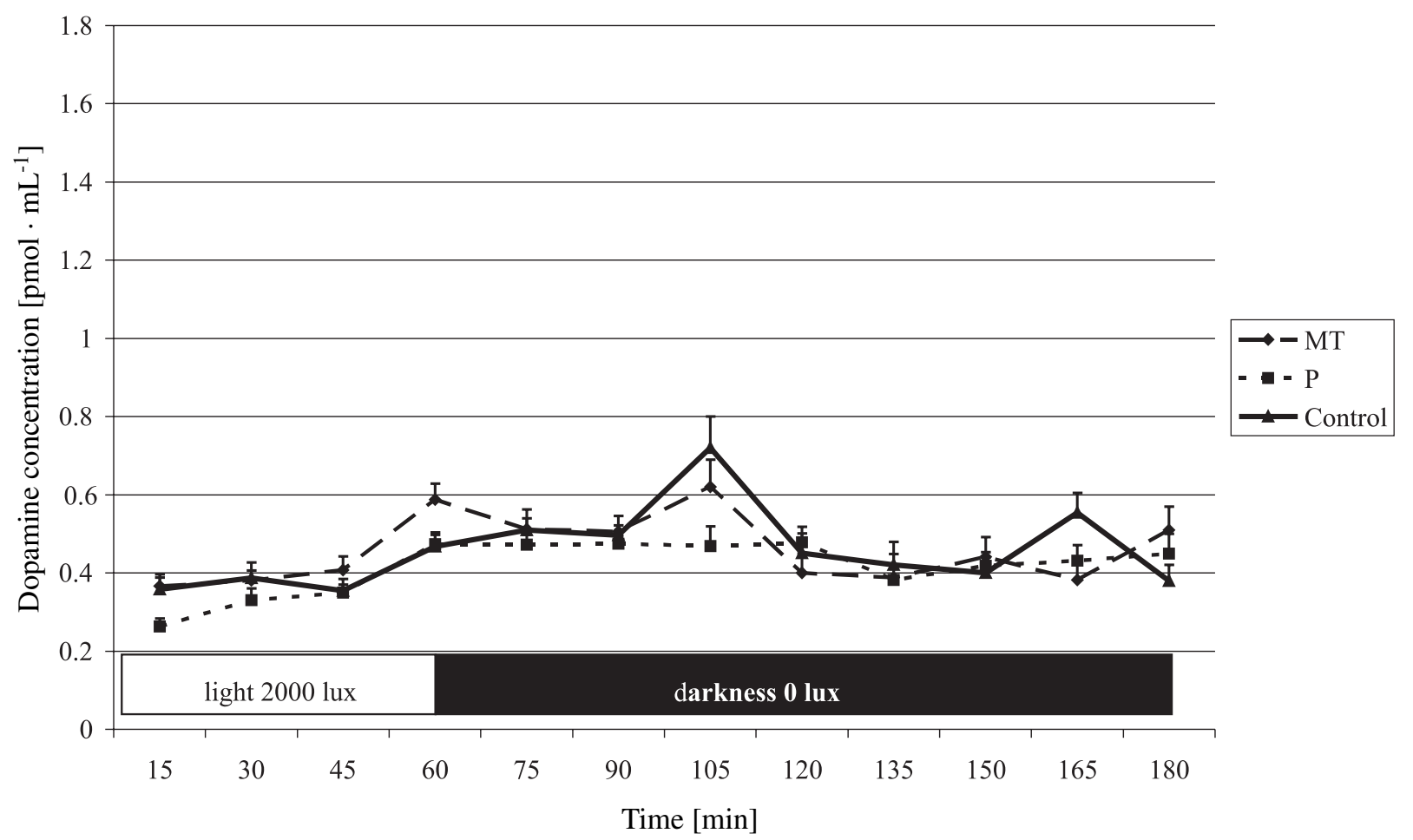

Fig. 3. Mean dopamine concentrations in the medium during hypothalamic perifusion of mature female carp in the winter $( \pm s)$; MT, hypothalami perifused in the presence of melatonin (dashed line); P, hypothalami with implanted pineal glands (dotted line); $\mathrm{C}$, control hypothalami (solid line)

melatonin may modulate the activity of the hypothalamic- ed by Zisapel and Laudon (1983), Zisapel et al. (1985) and pituitary-gonadal axis (Rollag et al. 1978, Lincoln and Rao and Mager (1987), who proved that melatonin can Short 1980, Arendt et al. 1981, Kennaway et al. 1983, inhibit dopamine secretion from hypothalamic cells in the Karsch et al. 1986). More accurate indications were provid- rat. The way in which melatonin affects reproductive 
processes has also been explored in fish. It was shown that melatonin affects changes in the circadian rhythm of LH release from the pituitary gland (Popek 1994b) but in an indirect way, because melatonin shows no influence on pituitary gonadotropes in carp (Popek et al. 2000). Other studies have excluded its direct effect on gonads and oocyte maturation (Popek et al. 1996), although it was shown that melatonin affects changes in the seasonal release of estradiol (Popek et al. 1997a) and it was even suggested that through steroids, it can affect the reproductive processes. However, these and other literature data fail to demonstrate the exact mechanism of melatonin influence on the hypothalamic-pituitary-gonadal axis in fish.

Considering the seasonality of the reproductive cycle in carp and the evident contribution of melatonin to circadian and seasonal synchronization of animal reproduction, the present experiment was performed in two diametrically opposed seasons of the year: in the summer, when sexual activity of the carp is at its highest, and in winter.

In in vivo experiments, where melatonin is injected into the brain of live fish, the interaction of other neurohormones, systems or feedbacks in the body cannot be ruled out. The observed effects of such experiments in the form of melatonin-induced changes in the dopaminergic activity of the hypothalamus can vary. However, to ensure that melatonin has a direct effect on dopamine secretion from the hypothalamus, in vitro studies were conducted outside the organism. The object of the studies were dissected hypothalami placed in perifusion columns filled with a flowing medium (Fig. 1). In the control group, hypothalami were only perifused with a physiological salt solution (pure medium). In the experimental groups, synthetic melatonin (MT) was dissolved in the medium and, for the sake of comparison; live pineal glands taken during the same time from the fish were implanted into the hypothalami $(\mathrm{P})$. During perifusion, medium temperature was constant in keeping with temperature of the water in which fish were kept, and varying photoperiod (light-dark) was applied. We used the observations of other authors (Gern and Greenhouse 1988, Kezuka et al. 1989), who showed that thanks to photoreceptive cells, fish pineal gland also reacts in vitro to changes in light intensity by changes in melatonin secretion, in exactly the same manner as in physiological conditions.

The results obtained in the summer have fully confirmed our hypotheses because in the hypothalamus not controlled by the body, exogenous melatonin was able to inhibit dopamine secretion. In the analysed samples of medium flowing from perifusion columns of group 1 (medium containing melatonin; MT), we showed dopamine concentration to be the lowest $\left(0.983\right.$ to $\left.0.573 \mathrm{pmol} \cdot \mathrm{mL}^{-1}\right)$ during the entire perifusion period. We also managed to show the effect of melatonin released into the medium directly from the implanted pineal glands (group 2; P). Initially, when the whole set of columns was illuminated (beginning of experiment to 60 minutes), dopamine concentration in particular samples was identical as in the control samples (group 3). After the columns were darkened, when melatonin released from implanted pineal glands appeared in the medium, dopamine concentration in the medium began to steadily decrease $\left(0.616 \mathrm{pmol} \cdot \mathrm{mL}^{-1}\right)$, drawing level with the concentration observed in group 1 . In the control group (pure medium; group 3), dopamine concentration in the samples was observed to increase in the first half of perifusion. After 90 minutes of the experiment, the concentration of this hormone reached a peak $\left(1.529 \mathrm{pmol} \cdot \mathrm{mL}^{-1}\right)$. Further on during perifusion, dopamine concentration gradually decreased, drawing level $\left(0.562 \mathrm{pmol} \cdot \mathrm{mL}^{-1}\right)$ with the values observed in groups 1 and 2 . It must be added that at 90 minutes of perifusion, differences in dopamine concentration in the medium between groups 1 (MT) and 2 (P), and group 3 (C), were highly significant $(P<0.01)$ (Fig. 2). These data confirm the results obtained by Hernandez-Rauda et al. (2000), who was studying the effect of exogenous melatonin on dopamine (DA) and 3,4dihydroxyphenylacetic acid (DOPAC) contents in hypothalamus and pituitary of rainbow trout. The increase in circulating melatonin was accompanied by a reduction in the amount of DOPAC in the hypothalamus and the pituitary. Those authors suggest that the inhibition of the hypothalamic-pituitary dopaminergic metabolism may be a specific mechanism of melatonin action in the trout brain that might operate following changes in the secretion of the hormone from the pineal gland.

During perifusion of the hypothalami taken from fish during winter regression, no differences in dopamine secretion were found between the groups (Fig. 3). Mean concentration of dopamine released from the hypothalami during perifusion in all the analysed groups was much lower $(P<0.05)$ than in the summer (in groups 2 and 3 ) (range of 0.263 to $0.620 \mathrm{pmol} \cdot \mathrm{mL}^{-1}$ ). There were not significant differences between summer and winter periods in group 1, where the level of dopamine in summer was as low as in winter. These results attest to the low activity of the hypothalamic dopaminergic system in the winter and confirm the hypothesis about the seasonal sensitivity of the dopaminergic system to melatonin. It is worth adding that previous research indicated that the pineal gland and melatonin only influence the hypothalamic-pituitary-gonadal axis during spawning (Popek 1991, Popek et al. 1991, 1997a, b, Popek and Epler 1999).

In conclusion, it is hypothesized that melatonin can be one of the major factors controlling LH release from the pituitary gland during the spawning period of carp. Probably this effect is stimulatory and involves inhibiting the hypothalamic secretion of dopamine.

\section{ACKNOWLEDGMENTS:}

This work was supported financially by the State Committee for Scientific Research (KBN), Poland (grants Nos. 5 P06D 01912 and 6 P06D 03921).

\section{REFERENCES}

Arendt J., Symons A.M., Laud C. 1981. Pineal function in the sheep: Evidence for a possible mechanism mediating seasonal reproductive activity. Experientia 37: 584-589. 
Breton B., Mikołajczyk T., Popek W. 1993. The neuroendocrine control of the gonadotropin $(\mathrm{GtH} 2)$ secretion in teleost fish. pp. 199-215. In: Lahlon B., Vitiello P. (eds.) Aquaculture: fundamental and applied research. Coastal and Estuarine Studies Series 43; American Geophysical Union, Washington, DC.

Cardinali D.P., Vacas M.I., Boyer E.E. 1979. Specific binding sites of melatonin in bovine brain. Endocrinology 105: 437-441.

Dubocovich M.L. 1983. Melatonin is a potent modulator of dopamine release in the retina. Nature 306: 782-784.

Dubocovich M.L. 1985. Characterization of a retinal melatonin receptor. Journal of Pharmacology and Experimental Therapeutics 234: 395-401.

Gallo R.V. 1980. Effect of manipulation of brain dopaminergic or serotoninergic systems on basal pulsatile LH release and perisuprachiasmatic-induced suppression of pulsatile LH release in ovariectomized rats. Neuroendocrinology 31: 161-167.

Gallo R.V. 1981. Pulsatile LH release during the ovulatory LH surge on proestrus in the rat. Biology of Reproduction 24: 100-104.

Gern W.A., Greenhouse S.S. 1988. Examination of in vitro melatonin secretion from superfused trout (Salmo gairdneri) pineal organs maintained under diel illumination or continuous darkness. General and Comparative Endocrinology 34: 163-174.

Hernandez-Rauda R., Miguez J.M., Ruibal C., Aldegunde M. 2000. Effects of melatonin on dopamine metabolism in the hypothalamus and the pituitary of the rainbow trout, Oncorhynchus mykiss. Journal of Experimental Zoology 287: 440-444.

Jalabert B., Szollosi D., Fostier A. 1973. Étude comparé de l' action des hormones hypophysaires et steroides sur la maturation in vitro de ovocytes de la Truite et du Carassin (Poissons téléosténs). Annales de Biologie Animale, Biochimie, Biophysique 13: 59-72.

Johnson G.A., Kupiecki R.M., Baker C.A. 1980. Single isotope derivative (radioenzymatic) method in measurement of catecholamines. Metabolism 29 (Suppl. 1): 1106-1113.

Karsch F.J., Bittman E.L., Robinson J.E., Yellon S.M., Wayne N.L., Olster D.H., Kaynard A.H. 1986. Melatonin and photorefractoriness: loss of response to the melatonin signal leads to seasonal reproductive transitions in the ewe. Biology of Reproduction 34: 265-274.

Kennaway D.J., Sanford L.M., Godfrey B., Friesen H.G. 1983. Patterns of progesterone melatonin and prolactin secretion in ewes maintained in four different photoperiods. Journal of Endocrinology 97: 229-242.

Kezuka H., Kobayashi M., Aida K., Hanyu I. 1989. Effects of photoperiod and pinealectomy on the gonadotropin surge and ovulation in goldfish Carassius auratus. Bulletin of the Japanese Society of Scientific Fisheries (Nippon Suisan Gakkaishi) 55: 2099-2103.

Lincoln G.A., Short R.V. 1980. Seasonal breeding: Nature's contraceptive. Recent Progress in Hormone Research 36: $1-52$.

Maywood E.S., Bittman E.L., Hastings M.H. 1996. Lesions of the melatonin- and androgen-responsive tissue of the dorso- medial nucleus of the hypothalamus block the gonadal response of male Syrian hamsters to programmed infusions of melatonin. Biology of Reproduction 54: 470-477.

Omeljaniuk R.J., Shih S.H., Peter R.E. 1987. In vivo evaluation of dopamine receptor-mediated inhibition of gonadotropin secretion from the pituitary gland of the goldfish, Carassius auratus. Journal of Endocrinology 114: 449-458.

Peter R.E., Chang J., Nahorniak C.S., Omeljaniuk R.J., Sokołowska M., Shih S.H., Billard R. 1986. Interactions of catecholamines and GnRH in regulation of gonadotropin secretion in teleost fish. Recent Progress in Hormone Research 42: 513-548.

Popek W. 1991. Rola szyszynki w rozwoju i dojrzewaniu gonad karpia (Cyprinus carpio L.). [The role of the pineal gland in development and maturation of carp (Cyprinus carpio L.) gonads.] Zeszyty Naukowe Akademii Rolniczej w Krakowie (157): 1-103. [In Polish.]

Popek W., Bieniarz K., Epler P. 1991. Role of the pineal gland in sexual cycle in common carp. pp. 99-102. In: Surowiak J., Lewandowski M.H. (eds.) Chronobiology and chronomedicine. Verlag Peter Lang, Frankfurt.

Popek W., Breton B., Piotrowski W., Epler P., Bieniarz K. 1994b. The role of the pineal gland in the control of a circadian pituitary-gonadotropin release rhythmicity in mature female carp (Cyprinus carpio L.). Neuroendocrinological Letters 16: $183-193$.

Popek W., Epler P. 1999. Effects of intraventricular melatonin microinjections on hypothalamic catecholamine activity in carp females during a year. Electronic Journal of Polish Agricultural Universities (www.ejpau.media.pl) 2 (1) Fisheries.

Popek W., Epler P., Bieniarz K., Sokołowska-Mikołajczyk M. 1997b. Contribution of factors regulating melatonin release from pineal gland of carp (Cyprinus carpio L.) in normal and in polluted environments. Archives of Polish Fisheries 5: 59-75.

Popek W., Epler P., Kime D.E., Sokołowska-Mikołajczyk M. 1996. Melatonin does not affect steroidogenesis or maturation of carp oocytes in vitro during the prespawning period. Polish Archives of Hydrobiology 43: 379-385.

Popek W., Galas J., Epler P. 1997a. The role of pineal gland in seasonal changes of blood estradiol level in immature and mature carp females. Archives of Polish Fisheries 5: 259-265.

Popek W., Luszczek-Trojnar E., Epler P. 2000. Effects of pineal gland and melatonin on maturation gonadotropin (GtH2) secretion from perifused pituitary glands of mature carp during spawning. Electronic Journal of Polish Agricultural Universities, (www.ejpau.media.pl) 3 (1) Fisheries.

Popek W., Natanek H., Bieniarz K., Epler P. 1994a. Seasonal changes in the catecholamine levels of the hypothalamus in mature and immature carp (Cyprinus carpio L.). Polish Archives of Hydrobiology 41: 227-236.

Rao M.L., Mager T. 1987. Influence of the pineal gland on pituitary function in humans. Psychoneuro-endocrinology 12: 141-147. 
Reiter R.J. 1991a. Pineal melatonin: Cell biology of its synthesis and of its physiological interactions. Endocrinology Reviews 12: 151-180.

Reiter R.J. 1991b. Melatonin: The chemical expression of darkness. Molecular and Cellular Endocrinology 79: C153-C159.

Rollag M.D., Morgan R.J., Niswender G.D. 1978. Route of melatonin secretion in sheep. Endocrinology 102: 1.

Stankov B., Capsoni S., Lucini V., Fauteck J., Gatti S., Gridelli B., Biella G., Cozzi B., Fraschini F. 1993. Autoradiographic localization of putative melatonin receptors in the brains of two Old World primates: Cercopithecus aethiops and Papio ursinus. Neuroscience 52: 459-468.

Weaver D.R., Rivkees S.A., Reppert S.M. 1989. Localization and characterization of melatonin receptors in rodent brain in vitro autoradiography. Journal of Neuroscience 9: 2581-2590.

Weaver D.R., Rivkees S.A., Carlson L.L., Reppert S.M. 1991. Localization of melatonin receptors in mammalian brain. pp. 289-308. In: Klein D.C., Moore R.Y., Reppert S.M. (eds.) Suprachiasmatic nucleus: The mind's clock. Oxford University Press, New York-Oxford.

Wuttke W., Cassell E., Meites J. 1971. Effects of ergocornine on serum prolactin and $\mathrm{LH}$, and on hypothalamic content of PIF and LRF. Endocrinology 88: 737-741.
Yu K.L., Peter R.E. 1990. Dopaminergic regulation of brain gonadotropin-releasing hormone in male goldfish during spawning behavior. Neuroendocrinology 52: 276-283.

Yu K.L., Peter R.E. 1992. Adrenergic and dopaminergic regulation of gonadotropin-releasing hormone release from goldfish preoptic-anterior hypothalamus and pituitary in vitro. General and Comparative Endocrinology 85: 138-146.

Yu K.L., Rosenblum P.M., Peter R.E. 1991. In vitro release of gonadotropin-releasing hormone from the brain preopticanterior hypothalamic region and pituitary of female goldfish. General and Comparative Endocrinology 81: 256-267.

Zachmann A., Knijf S.C.M., Bolliet V., Ali M.A. 1991. Effects of temperature cycles and photoperiod on rhythmic melatonin secretion from the pineal organ of a teleost (Catostomus commersoni) in vitro. Neuroendocrinological Letters 13: 325-330.

Zisapel N., Laudon M. 1983. Inhibition by melatonin of dopamine release from rat hypothalamus: regulation of calcium entry. Brain Research 272: 378-381.

Zisapel N., Egozi Y., Laudon M. 1985. Circadian variations in the inhibition of dopamine release from adult and newborn rat hypothalamus by melatonin. Neuroendocrinology 40: 102-108.

Received: 18 June 2005 Accepted: 15 November 2005 